\title{
Prognostic value of ST2 for MACEs and all-cause mortality in patients with coronary artery disease during a long-term follow up
}

\section{Man Li}

Chinese PLA General Hospital

Hongbin Liu ( $\nabla$ singlesail@126.com )

Lei Duan

Chinese PLA General Hospital

Yulun Cai

PLA Army General Hospital

Benchuan Hao

Chinese PLA General Hospital

Jianqiao Chen

Chinese PLA General Hospital

Huiying $\mathbf{L} \mathbf{i}$

Chinese PLA General Hospital

\section{Research}

Keywords: ST2, Coronary artery disease, Atherosclerosis, Biomarker

Posted Date: June 22nd, 2020

DOI: https://doi.org/10.21203/rs.3.rs-36063/v1

License: (c) (1) This work is licensed under a Creative Commons Attribution 4.0 International License. Read Full License 


\section{Abstract}

\section{Purpose}

ST2 has been proved the prognostic value in acute coronary syndrome (ACS), its prognostic value to predict cardiac events in established coronary artery disease (CAD) patients is unknown. The study ought to investigate the prognostic value of ST2 in patients with established coronary artery disease.

\section{Methods}

A total of 3650 consecutive patients were included in the study. The primary end point was major adverse cardiovascular events (MACEs). The secondary end point was all-cause death. To explore competing risks, cause-specific hazard ratios were obtained using Cox regression models.

Results

During a median follow up of 6.4 years, there were 775 patients had the occurrence of MACEs and 275 patients died. Kaplan-Meier survival estimates indicated that the patients with higher level of ST2 (ST2 > $19 \mathrm{ng} / \mathrm{ml}$ ) had a significantly increased risk of MACEs (log-rank $\mathrm{p}<0.001$ )and all-cause death(log-rank $\mathrm{p}<0.001)$. After adjustment for potential confounders, multiple COX regression models showed that higher level of ST2 was an independent predictor in developing MACEs(HR 1.31; 95\% Cl: 1.13-1.52; $p<0.001)$ and all-cause death(HR 1.78; $95 \% \mathrm{Cl}: 1.38-2.30 ; p<0.001)$. We saw a significant increase of AUC in ROC curve after addition of GDF-15 to a clinical model 0.586 vs 0.619 For MACEs $(p<0.001)$.For longterm all-cause death the increase of AUC 0.766 vs 0.642 ( $95 \% \mathrm{Cl} 0.787-0.846(p<0.001)$.

\section{Conclusion}

Higher level of ST2 is significantly associated with long-term all-cause death, MACEs and provides incremental prognostic value beyond traditional risks factors.

\section{Introduction}

Coronary artery disease (CAD) remains the leading cause of death of the world [1]. Patients with previous coronary heart disease have a high probability of major adverse cardiac events(MACEs). This underscore the need for development of reliable prognostic and outcome biomarker that would be of vital importance in established CAD patients. Suppression of tumorigenesis-2 (ST2) is an interleukin-1 (IL-1) receptor family member. It exists in two isoforms: membrane-bound and soluble isoforms [2]. Previous studies has been suggested that IL-33 acts as an "alarm" to alert potential tissue stress or damage.IL-33/ST2 signaling protects the myocardium against hypertrophy and cardiac fibrosis following pressure overload $[3,4]$. An IL-1-related protein, called interleukin (IL)-33 was identified as a functional ligand for ST2 [5].Soluble ST2 is identified as a novel biomarker in inflammatory conditions and cardiovascular disease. It has been widely reported that ST2 is a strong predictor of all-cause and cardiovascular mortality in patients with heart failure (HF) [6] [7] [8]. In ischemic heart disease, ST2 levels are elevated in non-ST 
segment elevation Acute Coronary Syndrome(NEST-ACS) and predict 1-year mortality [9]. In ST elevation myocardial infarction, ST2 levels in the upper quartile observed in ischemic heart disease(IHD) independently predict cardiovascular death and heart failure with an approximate doubling of risk [10].However, in long-term follow-up of CAD, whether ST2 is predictive of MACEs and all-cause remains inconclusive. We thus performed a large prospective large scale study. The aim of the present study is to evaluate the prognostic value of ST2 on MACEs and all-cause mortality in CAD during a long-term follow up.

\section{Subjects And Methods}

\subsection{The study population}

This study was an observational prospective study enrolling patients admitted as CAD in Chinese PLA general hospital between 2011 and 2015.A total of 4087 patients with an indication for diagnostic coronary angiography (CAG) and/or percutaneous coronary intervention (PCI) due to stable angina pectoris (SAP) or acute coronary syndrome (ACS) at our hospital were included.

All included patients were 18 years or older. Then 84 patients with the detailed data lost and 112 patients without angiographically determined CAD were excluded. 57 patients with one of the following diseases (severe heart failure, atrial fibrillation, aortic dissection, active infective disease, history of malignancy, end stage of renal disease, those in a deep coma) were excluded. 184 patients lost to follow-up were also excluded. As described in the flowchart, the final study group include 3650 patients. (Fig. 1).

Patients were considered to be hypertension with BP $>140 / 90 \mathrm{mmHg}$ or under anti-hypertensive medication. Hyperlipidemia was defined as known but untreated dyslipidemia or current treatment with lipid-lowering medications. Diabetes mellitus(DM) was defined as the presence of symptoms of diabetes and a resting plasma glucose concentration $\geq 200 \mathrm{mg} / \mathrm{dL}$, a fasting plasma glucose concentration $\geq$ $126 \mathrm{mg} / \mathrm{dL}$, a 2-h plasma glucose concentration $\geq 200 \mathrm{mg} / \mathrm{dL}$ in a $75 \mathrm{~g}$ oral glucose tolerance test, or taking hypoglycemic agent or other medications for DM. Current smoking was defined smoking if they reported any tobacco use in the last 30 days.

\subsection{Blood samples}

Blood samples were collected in the early morning. On the basis of protocol, the blood were obtained by the EDTA-anticoagulated plastic tubes. All the blood samples were centrifuged at $1000 \mathrm{~g}$ for $10 \mathrm{~min}$ and serum samples were stored at $₫ 80^{\circ} \mathrm{C}$. The plasma levels of total cholesterol (TC), high-density lipoprotein (HDL-C), low-density lipoprotein (LDL-C) and triglycerides (TG) levels were measured using commercial reagents following standard procedures. The ST2 levels were determined in serum in single measurements by using a quantitative sandwich monoclonal enzyme-linked immunosorbent assay (Presage ST2 Assay, Critical Diagnostics, Inc., San Diego, California).

\subsection{Follow up and outcomes}


Patients were followed up until February 2020 or until the occurrence of cardiovascular event. All participants were followed up by analyses of clinical materials and telephone contact quarterly. The primary endpoint was MACEs, the second endpoint was all-cause death. MACEs was defined as cardiac death, unstable angina, myocardial infarction and unplanned revascularization. All deaths were considered cardiac unless a definitive non cardiac cause was established. Myocardial infarction was defined as the rise of cardiac biomarkers with evidence of myocardial ischemia. Unstable angina pectoris was defined as new or accelerating symptoms of myocardial ischemia accompanied by new ischemic ST-T changes. Coronary revascularization was diagnosed if the patient underwent percutaneous coronary intervention $(\mathrm{PCl})$ or coronary artery bypass grafting $(\mathrm{CABG})$ with evidence of myocardial ischemia. We obtained follow-up for all patients until the primary outcome or date of censoring. All-cause death was defined as death from any cause. Written informed content was obtained from all study participants, and the study was approved by the ethics committee of Chinses PLA General Hospital.

\subsection{Statistical analysis}

Variables with a normal distribution are presented as mean $\pm \mathrm{SD}$, whereas in case of nonnormality the medians are presented. Categorical data are presented as counts or percentages. Patients were divided into two groups according to the median level of ST2 and differences in baseline characteristics between the two groups were evaluated by chi-square tests (categorical variables), analysis of variance as appropriate. Spearman correlation coefficient was used to assess the correlation between ST2 values and other continuous variables. Kaplan-Meier curves was used to estimate the cumulative incidence risks of outcomes across baseline ST2 levels and compared by log-rank tests. Cox proportional hazards models were used to evaluate the association of baseline ST2 levels with the study endpoints. The results are presented as the hazard ratios (HRs) and 95\% confidence intervals (Cls) according to levels of ST2.We fitted two multivariate proportional hazards models. Model 1 was adjusted for clinical variables include age, sex, BMI, current smokers, hypertension, hyperlipidemia, diabetes mellitus, previous myocardial infarction(MI), previous PCl/CABG,TC,TG,HDL-C,LDL-C. Model 2 was adjusted for ST2 level and Moedel1.The relation of ST2 levels with outcomes is presented with COX proportional hazard models both with ST2 as a continuous variable and with ST2 as a categorical variable. Area under ROC curve was used to compare the predictive ability of the parameters of interest. SPSS version 21.0 software (IBM Corp., Armonk, New York) was used for descriptive data analysis. All statistical tests were 2-tailed, and $p$ values $<0.05$ were considered statistically significant.

\section{Results}

\subsection{Baseline characteristics of CAD patients.}

Baseline measurements of ST2 were available in 3650 patients. The median concentration of ST2 was $19 \mathrm{ng} / \mathrm{ml}$. The baseline characteristics of the consecutive CAD patients are shown in Table 1. we divided the patients into two groups based on the median concentrations of ST2.Patients with ST2 $\geq 19 \mathrm{ng} / \mathrm{ml}$ 
was older, more often men, higher rate of previous PCI/CABG. They also had a higher level of TG. (Table 1).

Table 1

Baseline clinical and laboratory characteristics of the study patients according to ST2 levels

\begin{tabular}{|c|c|c|c|c|}
\hline & $\begin{array}{l}\text { Total } n= \\
3650\end{array}$ & $\begin{array}{l}\mathrm{ST2}(\geq 19 \mathrm{ng} / \mathrm{ml})(\mathrm{n}= \\
1818)\end{array}$ & $\begin{array}{l}\text { ST2( } \geq \\
19 \mathrm{ng} / \mathrm{ml}) \\
(\mathrm{n}=1832)\end{array}$ & $\begin{array}{l}\text { p value for } \\
\text { trend }\end{array}$ \\
\hline Age, years & $61.4(27-95)$ & $61.03(26-93)$ & $61.86(30-95)$ & 0.031 \\
\hline Male, n\% & $2633(72.1)$ & $1227(46.6)$ & 1406(53.4) & 0.000 \\
\hline $\mathrm{BMI}(\mathrm{kg} / \mathrm{m} 2)$ & $\begin{array}{l}25.64(13.3- \\
41)\end{array}$ & $25.7(13.3-41.0)$ & $\begin{array}{l}25.6(14.5- \\
39.7)\end{array}$ & 0.230 \\
\hline $\begin{array}{l}\text { Current smokers, } \mathrm{n} \\
(\%)\end{array}$ & 1668(45.82) & $810(48.6)$ & $858(51.4)$ & 0.086 \\
\hline Hypertension, n (\%) & 2372(65.00) & 1162(49) & $1210(51)$ & 0.090 \\
\hline Hyperlipidemia, n (\%) & 1120(30.70) & $581(51.9)$ & $539(48.1)$ & 0.099 \\
\hline $\begin{array}{l}\text { Diabetes mellitus, } \mathrm{n} \\
(\%)\end{array}$ & 1163(31.90) & $578(49.7)$ & $585(50.3)$ & 0.943 \\
\hline Previous MI, n (\%) & $254(6.98)$ & $125(6.88)$ & 129(7.04) & 0.085 \\
\hline $\begin{array}{l}\text { Previous PCl/CABG, n } \\
(\%)\end{array}$ & 2687(73.6) & 1287(70.79) & $1400(76.42)$ & 0.003 \\
\hline $\mathrm{TC}(\mathrm{mmol} / \mathrm{L})$ & $4.03 \pm 1.0$ & $4.03 \pm 1.09$ & $4.03 \pm 1.08$ & 0.816 \\
\hline $\mathrm{HDL}-\mathrm{C}(\mathrm{mmol} / \mathrm{L})$ & $1.07 \pm 0.68$ & $1.07 \pm 0.71$ & $1.07 \pm 0.65$ & 0.951 \\
\hline LDL-C(mmol/L) & $2.40 \pm 0.91$ & $2.38 \pm 0.85$ & $2.41 \pm 0.91$ & 0.314 \\
\hline $\mathrm{TG}(\mathrm{mmol} / \mathrm{L})$ & $1.62 \pm 1.21$ & $1.54 \pm 1.40$ & $1.7 \pm 0.98$ & 0.000 \\
\hline \multicolumn{5}{|l|}{ Medications } \\
\hline Aspirin, n (\%) & $3415(93.79 \%)$ & $1712(50.1)$ & 1703(49.9) & 0.138 \\
\hline ACEI, n (\%) & $1503(41.28 \%)$ & $720(47.1)$ & $810(52.9)$ & 0.530 \\
\hline$\beta$-blocker, n(\%) & $1629(44.74 \%)$ & $1289(49.0)$ & $1340(51.0)$ & 0.096 \\
\hline Statins, n (\%) & $3442(94.30 \%)$ & $1725(50.1)$ & 1717(49.9) & 0.153 \\
\hline
\end{tabular}

\subsection{Correlations of ST2 levels with other clinical biochemical factors}


Patients with higher levels of ST2 at presentation were older, more males, higher rate of previous $\mathrm{PCl} / \mathrm{CABG}$, higher level of TG(Table 2).ST2 levels were not associated with other variables (BMI, smoking, hypertension, hyperlipidemia, diabetes mellitus, previous MI,TC,HDL-C,LDL-C, aspirin use ,ACEI use, $\beta$ blocker use ,statins use.).Multiple regression analysis indicated that ST2 was independently associated with age $(p<0.001)$, male sex $(p<0.001)$, TG $(p<0.001)$.

Table 2

Spearman's correlation coefficients between ST2 and clinical and biochemical parameters

\begin{tabular}{|c|c|c|c|c|}
\hline & $\begin{array}{l}\mathrm{ST2}(\geq 19 \mathrm{ng} / \mathrm{ml})(\mathrm{n}= \\
1818)\end{array}$ & $\begin{array}{l}\text { ST2( } \\
19 \mathrm{ng} / \mathrm{ml}) \\
(n=1832)\end{array}$ & coefficient & $\begin{array}{l}\text { spearman } \\
\text { correlation(p) }\end{array}$ \\
\hline Age, years & $61.03(26-93)$ & $61.86(30-95)$ & 0.036 & 0.031 \\
\hline Male ,n\% & $1227(46.6)$ & $1406(53.4)$ & 0.103 & 0.000 \\
\hline $\mathrm{BMI}(\mathrm{kg} / \mathrm{m} 2)$ & $25.7(13.3-41.0)$ & $\begin{array}{l}25.6(14.5- \\
39.7)\end{array}$ & -0.019 & 0.244 \\
\hline $\begin{array}{l}\text { Current smokers, n } \\
(\%)\end{array}$ & $810(48.6)$ & $858(51.4)$ & 0.023 & 0.162 \\
\hline Hypertension, n (\%) & 1162(49) & $1210(51)$ & 0.023 & 0.170 \\
\hline Hyperlipidemia, n (\%) & $581(51.9)$ & $539(48.1)$ & -0.028 & 0.092 \\
\hline $\begin{array}{l}\text { Diabetes mellitus, } \mathrm{n} \\
(\%)\end{array}$ & $578(49.7)$ & $585(50.3)$ & 0.002 & 0.919 \\
\hline Previous MI, n (\%) & $125(6.88)$ & $129(7.04)$ & 0.001 & 0.983 \\
\hline $\begin{array}{l}\text { Previous PCl/CABG, } \\
\text { n (\%) }\end{array}$ & 1287(70.79) & $1400(76.42)$ & 0.052 & 0.002 \\
\hline $\mathrm{TC}(\mathrm{mmol} / \mathrm{L})$ & $4.03 \pm 1.09$ & $4.03 \pm 1.08$ & 0.004 & 0.802 \\
\hline $\mathrm{HDL}-\mathrm{C}(\mathrm{mmol} / \mathrm{L})$ & $1.07 \pm 0.71$ & $1.07 \pm 0.65$ & 0.010 & 0.544 \\
\hline LDL-C(mmol/L) & $2.38 \pm 0.85$ & $2.41 \pm 0.91$ & 0.005 & 0.788 \\
\hline $\mathrm{TG}(\mathrm{mmol} / \mathrm{L})$ & $1.54 \pm 1.40$ & $1.7 \pm 0.98$ & 0.077 & 0.000 \\
\hline \multicolumn{5}{|l|}{ Medications } \\
\hline Aspirin, n (\%) & $1712(50.1)$ & $1703(49.9)$ & -0.025 & 0.136 \\
\hline ACEI, n (\%) & $720(47.1)$ & $810(52.9)$ & 0.047 & 0.005 \\
\hline$\beta$-blocker, n(\%) & $1289(49.0)$ & $1340(51.0)$ & 0.028 & 0.089 \\
\hline Statins, n(\%) & $1725(50.1)$ & 1717(49.9) & -0.024 & 0.147 \\
\hline
\end{tabular}


ST2 was elevated in patients who experienced the primary end point (median $21.66 \mathrm{ng} / \mathrm{mL}, \mathrm{P}<0.001$ ) and the secondary end points (median $26.38 \mathrm{ng} / \mathrm{mL}, \mathrm{P}<0.001$ ) when compared with event-free survivors (median $18.50 \mathrm{ng} / \mathrm{mL}$ ) and (median $18.74 \mathrm{ng} / \mathrm{mL}, \mathrm{P}<0.001$ ) (Fig. 2)

\section{Primary endpoint}

During the median follow up of 6.4 years, MACEs was occurred in 775(21.2\%) patients. In patients with higher ST2 levels(ST2 level $\geq 19 \mathrm{ng} / \mathrm{ml}$ ) was had a significantly higher level of MACEs rate compared with the lower levels(ST2 level $\geq 19 \mathrm{ng} / \mathrm{ml})(17.9 \%$ versus $24.8 \%)$.

Figure3a shows the cumulative event free survival curves for MACEs stratified according to ST2 levels. Patients with high ST2 were more likely to have a high MACEs rates (log-rank test, $p<0.0001$ ). We then applied Cox proportional-hazards models to assess the long term prognostic value of ST2 on MACEs ,the HR was $1.36(95 \% \mathrm{Cl}, 1.17-1.58)$. After incorporating age, sex, and other clinically relevant covariates, the adjusted RR fell to $1.31(95 \% \mathrm{Cl}, 1.14-1.52)$ (Table 3$)$.

Table 3

Relation of the ST2 level and MACEs in univariate and multivariate survival analysis

\begin{tabular}{|lllllll|}
\hline \multicolumn{7}{|c|}{ Independent Predictors of Major Adverse Cardiac Events } \\
& Univariate Models & \multicolumn{4}{l|}{ Multivariate Models } \\
& HR & $95 \% \mathrm{Cl}$ & $\mathrm{p}$ & $\mathrm{HR}$ & $95 \% \mathrm{Cl}$ & $\mathrm{p}$ \\
\hline Age & 1.020 & $1.013-1.026$ & 0.000 & 1.020 & $1.014-1.027$ & $<0.001$ \\
\hline Sex & 1.185 & $1.153-1.211$ & 0.396 & - & - & - \\
\hline Previous PCl/CABG & 1.319 & $1.111-1.565$ & 0.002 & 1.351 & $1.136-1.606$ & 0.001 \\
\hline Hypertension & 1.329 & $1.139-1.555$ & 0.000 & 1.218 & $1.041-1.426$ & 0.014 \\
\hline Diabetes & 1.230 & & & 1.230 & $1.063-1.425$ & 0.006 \\
\hline Hyperlipidemia & 1.001 & $0.079-1.032$ & 0.087 & - & - & - \\
\hline ST2 $\geq 19 \mathrm{ng} / \mathrm{ml}$ & REF & & & REF & & \\
\hline ST2 $\geq 19 \mathrm{ng} / \mathrm{ml}$ & 1.360 & $1.168-1.579$ & 0.000 & 1.313 & $1.137-1.517$ & $<0.001$ \\
\hline
\end{tabular}

\section{Secondary endpoint}

During the follow up, 275(7.4\%) patients died. Compared with participants in the lower level of ST2, the higher level group had significantly higher incidence of all-cause death.( $4.9 \%$ versus $10.0 \%$ ). Figure $3 b$ shows the cumulative event free survival curves for all cause death stratified according to ST2 levels. Patients with high ST2 were more likely to have a high all-cause death rates (log-rank test, $\mathrm{p}<$ 0.0001).COX proportional-hazards model revealed that, the $\mathrm{HR}(95 \% \mathrm{Cl})$ of all-cause deaths for those in 
the higher level of ST2 was $2.00(95 \% \mathrm{Cl}, 1.56-2.59)$ in unadjusted analysis. After adjusting for the same covariates, the cause-specific HR for all cause death was 1.78 (95\% Cl, 1.38-2.30) (Table 4)

Table 4

Relation of the ST2 level and all cause death in univariate and multivariate survival analysis

\begin{tabular}{|lllllll|}
\hline \multicolumn{7}{|c|}{ Independent Predictors of All-cause death } \\
& Univariate Models & \multicolumn{4}{ll}{ Multivariate Models } \\
\hline & $\mathrm{HR}$ & $95 \% \mathrm{Cl}$ & $\mathrm{p}$ & $\mathrm{HR}$ & $95 \% \mathrm{Cl}$ & $\mathrm{p}$ \\
\hline Age & 1.085 & $1.074-1.097$ & $<0.001$ & 1.080 & $1.068-1.092$ & $<0.001$ \\
\hline Sex & 1.187 & $1.123-1.244$ & 0.405 & - & - & - \\
\hline Hypertension & 1.175 & $1.170-1.179$ & 0.040 & 1.085 & $1.035-1.157$ & 0.054 \\
\hline Hyperlipidemia & 1.344 & $1.266-1.522$ & 0.018 & 1.271 & $1.235-1.341$ & 0.032 \\
\hline DM & 1.454 & $1.142-1.851$ & 0.002 & 1.345 & $1.055-1.715$ & 0.017 \\
\hline ST2 $\geq 19 \mathrm{ng} / \mathrm{ml}$ & REF & & & REF & & \\
\hline ST2 $\geq 19 \mathrm{ng} / \mathrm{ml}$ & 2.009 & $1.561-2.586$ & $<0.001$ & 1.781 & $1.380-2.298$ & $<0.001$ \\
\hline
\end{tabular}

\subsection{Incremental value of ST2 over conventional risk factors}

Receiver operating characteristic curves (ROC) were constructed to determine the predictive value of ST2 over conventional risk factors. Model 1 is combination of conventional factors, Model 2 include ST2 and Model 1.

Area under the curve (AUC) for each model was calculated. For MACEs: ROC curve analyses indicated that AUC (area under the curve) were 0.586 ( $95 \% \mathrm{Cl} 0.559-0.603$ ) for clinical model(model1), 0.619 (95\% $\mathrm{Cl} 0.605-0.638)$ for clinical model including ST2 $\square$ model2 2 . There was a significant difference compared to the clinical model with ST2 ( $<<0.001)$ (Fig. 4a).

For all-cause mortality: ROC curve analyses showed that AUC were 0.642 ( $95 \% \mathrm{Cl} 0.594-0.701)$ for clinical model(model1) 0.766 ( $95 \% \mathrm{Cl} 0.717-0.806)$ for clinical model includingST2. ROC curve analysis indicated that there was a significant difference compared to the clinical model with $S T 2(p<0.001)$ (Fig. 4b).

\section{Discussion}

Our study established a higher level of ST2 was a significant and independent predictor of cardiovascular event. In this study, we found that higher concentrations of ST2 $(\geq 19 \mathrm{ng} / \mathrm{ml})$ was associated with an increased risk of all-cause death in patients with coronary heart disease. Higher concentrations of ST2 remained an independent indicator of MACEs and all-cause mortality after adjustment for established 
risk factors for $\mathrm{CV}$ disease and other prognostic biomarkers. Furthermore, our study confirmed that the incremental prognostic value of ST2 for MACEs and all-cause mortality beyond the clinical model by ROC curve analysis .Our results provide updated information on the long-term prognostic role of ST2 in established CAD patients. Our results suggest that the addition of plasma ST2 measurements to established CV risk factors may further improve risk stratification.

Biomarkers have become increasingly important tools helping to improve patient care over the past two decades. Numerous biomarkers have been identified in the diagnosis, prognosis and risk prediction of cardiovascular disease but few have made their way to clinical practice [11]. The most extensively used cardiovascular biomarkers are the natriuretic peptides in the diagnosis and prognosis of heart failure and cardiac troponins in the diagnosis of acute myocardial infarction. Deeper experimental studies of the pathophysiology of atherosclerosis have identified a large number of molecules as potential prognostic biomarkers in cardiovascular disease[12].Previous studies suggested that ST2 maybe a potential biological marker for mechanical overload in the heart.ST2 was markedly upregulated in mechanicallystimulated cardiomyocytes. Furthermore, ST2 has been proved to be a predictor of outcome in patients with HF [6] [13] [8] [14].Recent evidences suggest that ST2 may be predictive in patients with ACS [15] [16]. It has been shown to be a powerful independent prognosticator for patients with acute myocardial infarction (AMI) [6] [7].According to Eggers KM 's research, ST2 levels are elevated early in NSTE-ACS and predict 1-year mortality [9]. Wang YP's research showed that Serum levels of ST2, IL-33 and BNP were positively correlate with MACEs in patients with acute myocardial infarction (AMI) after percutaneous coronary intervention (PCI) [17].However, there was no to investigate the long-term value of ST2 in the prediction of MACEs or all cause death in patients with CAD in a large population.

The inflammatory hypothesis of atherosclerosis suggests that inflammatory cell signaling drives the formation, development, and eventual instability of atherosclerotic plaques [18]. Under this respect, the IL33-ST2 pathway deserves consideration. In fact, ST2 are particularly expressed in arterial endothelial cells, involving in the progression of atherosclerosis [19] [20].IL-33 was originally reported as a modulator of inflammation, tipping the balance towards CD $4+T$ helper-cell type 2 mediated immune responses [21]. IL-33 may play a protective role in the development of atherosclerosis. The effect of IL-33 on the function of foam cells indicated the protect role of IL-33 in atherosclerosis [22]. ST2 acts as a decoy receptor for IL-33, thus blocking its protective effects. It has been reported that mice treated with soluble ST2 developed significantly larger atherosclerotic plaques in the aortic sinus of the $A p o E(-/-)$ mice compared with the control mice [23].These results suggested that ST2 may be proposed as a marker of plaque burden and predictors of future cardiovascular event [24].Although the above data suggest that ST2 has a role in the prognosis of patients presenting with an acute coronary syndrome, whether ST2 contributes to cardiovascular risk prediction in a large scale CAD patients during a long-term follow up remains uncertain.

To evaluate the prognostic value of a biomarker in CVD, researchers must demonstrate the elevated risk of an cardiovascular events associated with higher levels of the new biomarker with adjustment for other established risk factors. The results should be presented as hazards ratios relative risk estimates from a 
Cox model and a probability value test of significance of the marker in the multivariable models [25]. Our result indicated that after incorporating age, sex, and other clinically relevant covariates, the adjusted HR for MACEs and all cause death was 1.31 and 1.78 respectively in COX proportional-hazards models. Moreover, in the previous studies, the follow-up time for the predictive value of ST2 was relatively short. Brown et al assess the prognostic value of ST2 during a short-term follow up of 30 days for acute MI, ACS, and MACEs [26], Aldous et al revisited the prognostic value of ST2 in patients with chest pain with a longer follow-up of 18 months [27].Two reports were based on data from 3 clinical trials in ST elevation $\mathrm{MI}$ (STEMI) that provided data on the prognostic value of plasma ST2 for 30 days after MI for adverse events, and a further article reported prognostic performance over an average follow-up time of 20 months [16] [28] [29]. Our result demonstrated that in a median follow up of 6.4 years, higher level of ST2 is significantly associated with all-cause death, MACEs and provides incremental prognostic value beyond traditional risks factors.

\section{Limitations}

While the study provides a large, well characterized study sample with adjudicated outcomes, the research is limited to a single center, these data represent the results of an observational analysis in a clinical trial population. As in any observational study, we cannot exclude residual confounding. However, this is probably minimal because we used a comprehensive adjustment strategy to control for known variables that are commonly used to stratify the risk of CAD patients.

\section{Conclusions}

Higher values of ST2 confer a markedly adverse prognosis characterized by a large excess risk of MACEs and all-cause death over a long period of follow-up. Measurement of ST2 should be considered as part of approaches to risk stratification in CAD patients during a long-term follow up.

\section{Abbreviations}




\begin{tabular}{|c|c|}
\hline CAD & coronary artery disease \\
\hline MACEs & major adverse cardiovascular events \\
\hline ST2 & suppression of tumorigenesis-2 \\
\hline IL-1 & interleukin-1 \\
\hline IL-33 & interleukin-33 \\
\hline ACS & acute coronary syndrome \\
\hline NEST-ACS & non-ST segment elevation acute coronary syndrome \\
\hline HF & heart failure \\
\hline IHD & ischemic heart disease \\
\hline CAG & coronary angiography \\
\hline $\mathrm{PCl}$ & percutaneous coronary intervention \\
\hline CABG & coronary artery bypass grafting \\
\hline DM & diabetes mellitus \\
\hline MI & myocardial infarction \\
\hline HDL-C & high-density lipoprotein cholesterol \\
\hline LDL-C & low-density lipoprotein cholesterol \\
\hline TG & triglycerides \\
\hline $\mathrm{TC}$ & total cholesterol \\
\hline HR & hazard ratio \\
\hline CVD & cardiovascular disease \\
\hline ROC & receiver operating characteristic curves \\
\hline HR & hazard ratio \\
\hline AUC & area under the curve \\
\hline
\end{tabular}

\section{Declarations}

\section{Competing interests}

The authors declare that they have no competing interests

\section{Ethics approval}


This study was approved by the Ethics Board of the Chinese PLA General Hospital

\section{Consent for publication}

Not applicable

\section{Consent to participate}

Written informed consent was obtained from each patient.

\section{Availability of data and material}

The datasets used and/or analyzed during the current study are available from the corresponding author on reasonable request.

\section{Funding}

This work was supported by the Key Projects of Logistics Scientific Research Project of Chinese PLA(17BJZ48)and the National Key Research Program of China (2017YFC0840103)

\section{Authors' contributions}

Hongbin Liu and Man Li contributed to study design. Man Li contributed to data collection, data interpretation, and critical review of the manuscript drafting the manuscript. Lei Duan, Yulun Cai, Huiying $\mathrm{Li}$, Benchuan Hao, Jianqiao Chen contributed to data collection. All authors read and approved the final manuscript.

\section{Acknowledgements}

Not applicable

\section{References}

1. Timmis A, Townsend N, Gale C, Grobbee R, Maniadakis N, Flather M, et al. European Society of Cardiology: Cardiovascular Disease Statistics 2017. Eur Heart J. 2018;39(7):508-79.

2. Pichery M, Mirey E, Mercier P, Lefrancais E, Dujardin A, Ortega N, et al. Endogenous IL-33 is highly expressed in mouse epithelial barrier tissues, lymphoid organs, brain, embryos, and inflamed tissues: in situ analysis using a novel II-33-LacZ gene trap reporter strain. J Immunol. 2012;188(7):3488-95.

3. Kolodin D, van Panhuys N, Li C, Magnuson AM, Cipolletta D, Miller CM, et al. Antigen- and cytokinedriven accumulation of regulatory T cells in visceral adipose tissue of lean mice. Cell Metab. 
2015;21(4):543-57.

4. Odegaard JI, Lee MW, Sogawa Y, Bertholet AM, Locksley RM, Weinberg DE, et al. Perinatal Licensing of Thermogenesis by IL-33 and ST2. Cell. 2016;166(4):841-54.

5. Schmitz J, Owyang A, Oldham E, Song Y, Murphy E, McClanahan TK, et al. IL-33, an interleukin-1-like cytokine that signals via the IL-1 receptor-related protein ST2 and induces T helper type 2-associated cytokines. Immunity. 2005;23(5):479-90.

6. Emdin M, Aimo A, Vergaro G, Bayes-Genis A, Lupón J, Latini R, et al. sST2 Predicts Outcome in Chronic Heart Failure Beyond NT-proBNP and High-Sensitivity Troponin T. J Am Coll Cardiol. 2018;72(19):2309-20.

7. Hughes MF, Appelbaum S, Havulinna AS, Jagodzinski A, Zeller T, Kee F, et al. ST2 may not be a useful predictor for incident cardiovascular events, heart failure and mortality. Heart. 2014;100(21):1715-21.

8. Aleksova A, Paldino A, Beltrami AP, Padoan L, lacoviello M, Sinagra G, et al. Cardiac Biomarkers in the Emergency Department: The Role of Soluble ST2 (sST2) in Acute Heart Failure and Acute Coronary Syndrome-There is Meat on the Bone. J Clin Med. 2019;8(2).

9. Eggers KM, Armstrong PW, Califf RM, Simoons ML, Venge P, Wallentin L, et al. ST2 and mortality in non-ST-segment elevation acute coronary syndrome. Am Heart J. 2010;159(5):788-94.

10. Richards AM, Di Somma S, Mueller T. ST2 in stable and unstable ischemic heart diseases. Am J Cardiol. 2015;115(7 Suppl):48B-58B.

11. Lyngbakken MN, Myhre PL, Røsjø H, Omland T. Novel biomarkers of cardiovascular disease: Applications in clinical practice. Crit Rev Clin Lab Sci. 2019;56(1):33-60.

12. Libby P, Theroux P. Pathophysiology of coronary artery disease. Circulation. 2005;111(25):3481-8.

13. Aimo A, Januzzi JL, Vergaro G, Richards AM, Lam CSP, Latini R, et al. Circulating levels and prognostic value of soluble ST2 in heart failure are less influenced by age than N-terminal pro-B-type natriuretic peptide and high-sensitivity troponin T. Eur J Heart Fail. 2020.

14. van Vark LC, Lesman-Leegte I, Baart SJ, Postmus D, Pinto YM, Orsel JG, et al. Prognostic Value of Serial ST2 Measurements in Patients With Acute Heart Failure. J Am Coll Cardiol. 2017;70(19):237888.

15. Salvagno GL, Pavan C. Prognostic biomarkers in acute coronary syndrome. Ann Transl Med. 2016;4(13):258.

16. Shimpo M, Morrow DA, Weinberg EO, Sabatine MS, Murphy SA, Antman EM, et al. Serum levels of the interleukin-1 receptor family member ST2 predict mortality and clinical outcome in acute myocardial infarction. Circulation. 2004;109(18):2186-90.

17. Wang Y-P, Wang J-H, Wang X-L, Liu J-Y, Jiang F-Y, Huang X-L, et al. Roles of ST2, IL-33 and BNP in predicting major adverse cardiovascular events in acute myocardial infarction after percutaneous coronary intervention. J Cell Mol Med. 2017;21(11):2677-84. 
18. Zhao TX, Mallat Z. Targeting the Immune System in Atherosclerosis: JACC State-of-the-Art Review. J Am Coll Cardiol. 2019;73(13):1691-706.

19. Bartunek J, Delrue L, Van Durme F, Muller O, Casselman F, De Wiest B, et al. Nonmyocardial production of ST2 protein in human hypertrophy and failure is related to diastolic load. J Am Coll Cardiol. 2008;52(25):2166-74.

20. Liu J, Wang W, Wang L, Chen S, Tian B, Huang K, et al. IL-33 Initiates Vascular Remodelling in Hypoxic Pulmonary Hypertension by up-Regulating HIF-1a and VEGF Expression in Vascular Endothelial Cells. EBioMedicine. 2018;33:196-210.

21. Kakkar R, Lee RT. The IL-33/ST2 pathway: therapeutic target and novel biomarker. Nat Rev Drug Discov. 2008;7(10):827-40.

22. McLaren JE, Michael DR, Salter RC, Ashlin TG, Calder CJ, Miller AM, et al. IL-33 reduces macrophage foam cell formation. J Immunol. 2010;185(2):1222-9.

23. Junttila MJ, Hookana E, Kaikkonen KS, Kortelainen M-L, Myerburg RJ, Huikuri HV. Temporal Trends in the Clinical and Pathological Characteristics of Victims of Sudden Cardiac Death in the Absence of Previously Identified Heart Disease. Circ Arrhythm Electrophysiol. 2016;9(6).

24. Aimo A, Migliorini P, Vergaro G, Franzini M, Passino C, Maisel A, et al. The IL-33/ST2 pathway, inflammation and atherosclerosis: Trigger and target? Int J Cardiol. 2018;267:188-92.

25. Vasan RS. Biomarkers of cardiovascular disease: molecular basis and practical considerations. Circulation. 2006;113(19):2335-62.

26. Brown AM, Wu AHB, Clopton P, Robey JL, Hollander JE. ST2 in emergency department chest pain patients with potential acute coronary syndromes. Ann Emerg Med. 2007;50(2).

27. Aldous SJ, Richards AM, Troughton R, Than M. ST2 has diagnostic and prognostic utility for allcause mortality and heart failure in patients presenting to the emergency department with chest pain. J Card Fail. 2012;18(4):304-10.

28. Sabatine MS, Morrow DA, Higgins LJ, MacGillivray C, Guo W, Bode C, et al. Complementary roles for biomarkers of biomechanical strain ST2 and N-terminal prohormone B-type natriuretic peptide in patients with ST-elevation myocardial infarction. Circulation. 2008;117(15):1936-44.

29. Dhillon OS, Narayan HK, Khan SQ, Kelly D, Quinn PA, Squire IB, et al. Pre-discharge risk stratification in unselected STEMI: is there a role for ST2 or its natural ligand IL-33 when compared with contemporary risk markers? Int J Cardiol. 2013;167(5):2182-8.

\section{Figures}


4087patients from 2011 to 2015

with established CAD

84 patients with detailed data lost

57 patients with severe heart failure, atrial fibrillation, aortic dissection, active infective disease, history of malignancy, and end stage of renal disease and those in a deep coma were excluded.

112 patients without angiographically determined $C A D$

3891 CAD patients
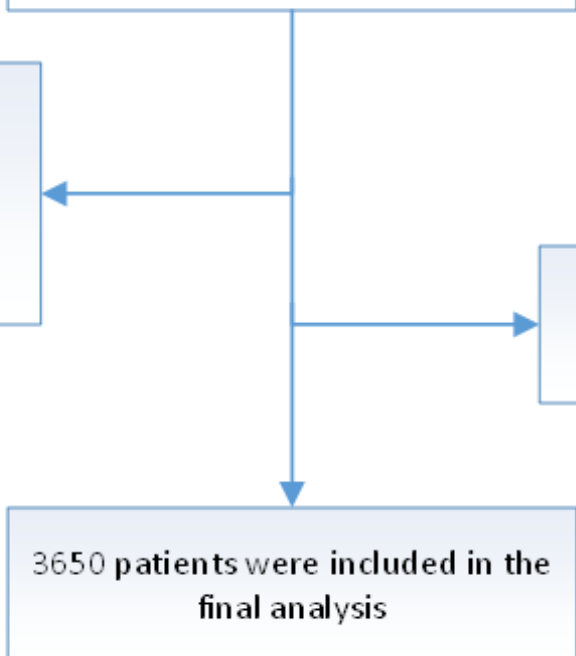

184 patients lost follow up final analysis

\section{Figure 1}

Flowchart of the study 

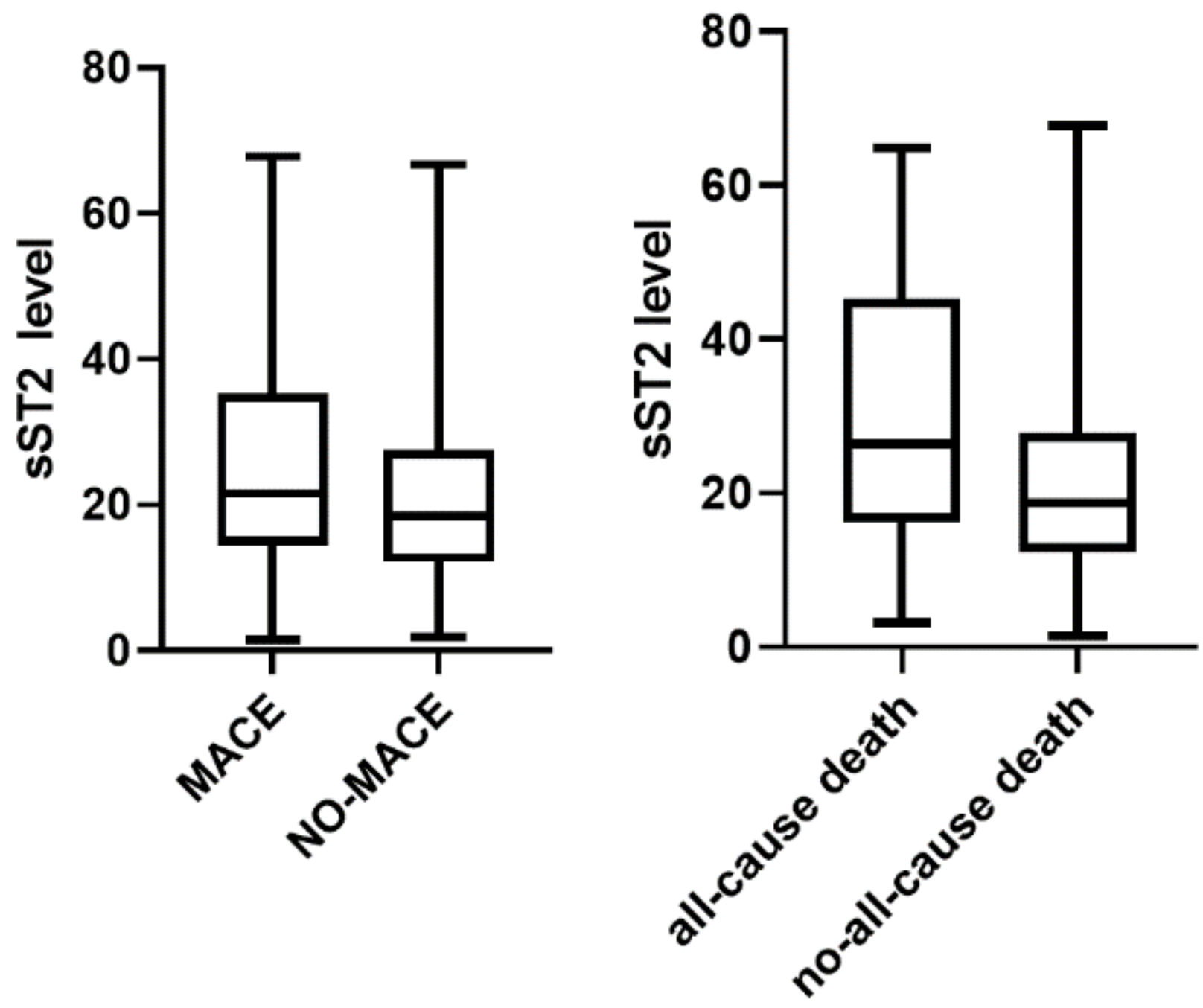

Figure 2

ST2 levels in in patients who experienced the cardiovascular events and event-free survivors 


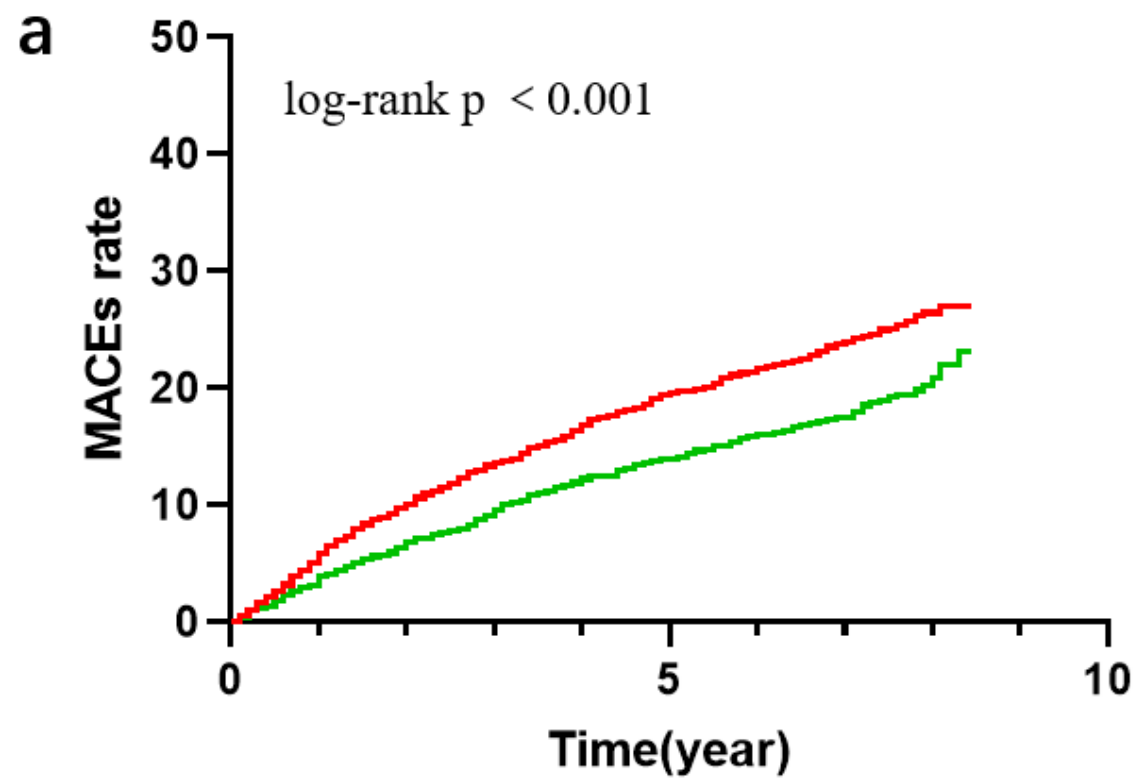

- sST2 level $\geqslant 19 \mathrm{ng} / \mathrm{ml}$

— sST2 level $<19 \mathrm{ng} / \mathrm{ml}$

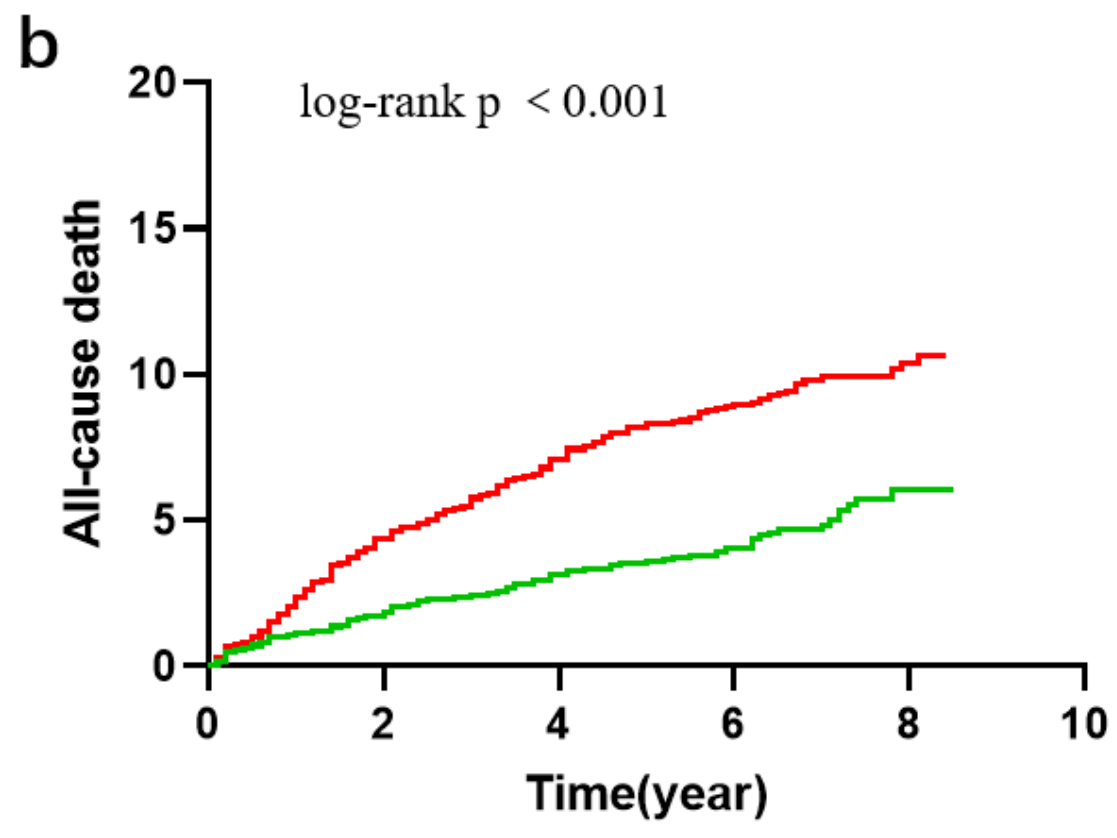

Figure 3

Kaplan-Meier curves for prediction of MACEs(a) and all-cause death in patients with higher levels of ST2 $(\mathrm{ST} 2 \geq 19 \mathrm{ng} / \mathrm{ml})$ and lower levels of ST2 $2 \mathrm{ST} 2 \bigotimes 19 \mathrm{ng} / \mathrm{ml} \rrbracket$ 


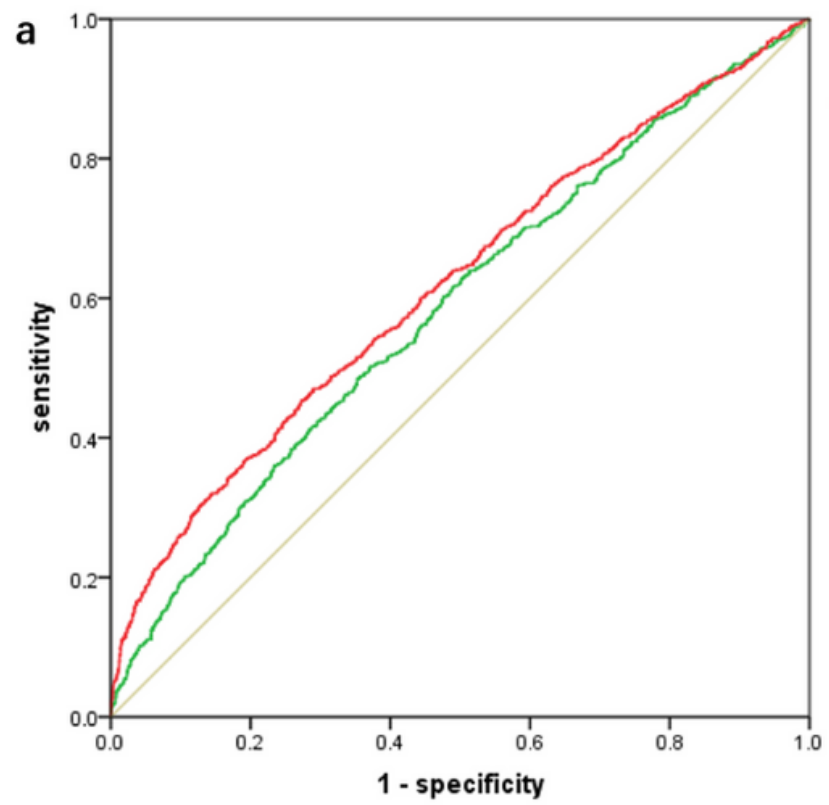

— Model1 Conventional(AUC $=0.586$ )

Model2 Conventional $+\mathrm{ST} 2(\mathrm{AUC}=0.619)$

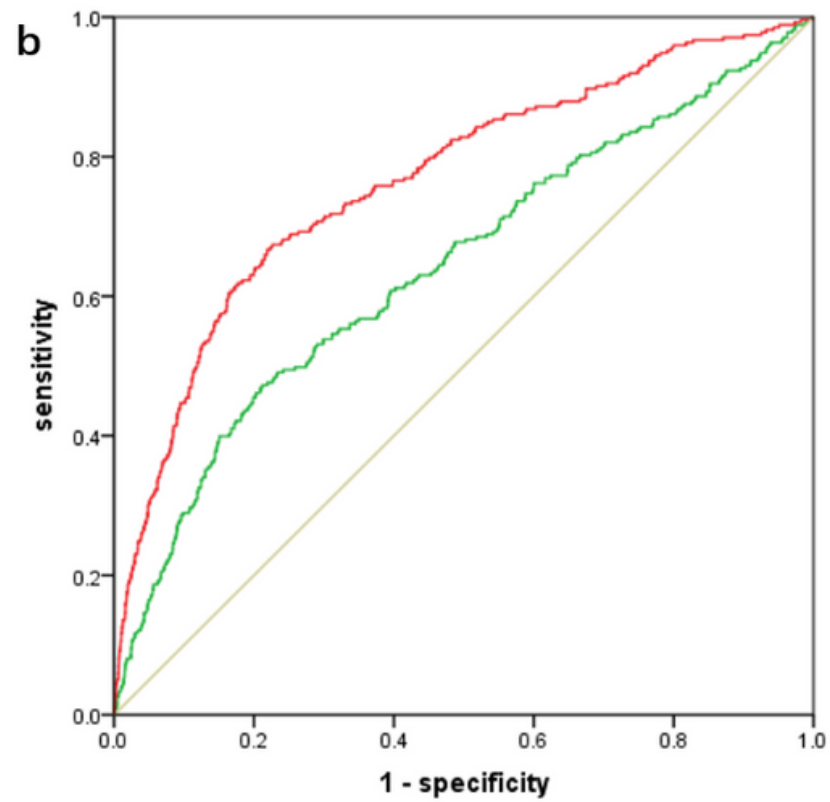

Model1 Conventional $(\mathrm{AUC}=0.642)$
Model2 Conventional $+\mathrm{ST} 2(\mathrm{AUC}=0.766)$

\section{Figure 4}

ROC curve analyses that relate ST2 levels to MACEs (a) and all-cause death (b). 